\title{
Theoretical and experimental study of a synchronal rotary multiphase pump at very high inlet gas volume fractions
}

Xu Yang*, Congcong $\mathrm{Hu}$, Yao Hu, Zongchang Qu

School of Energy and Power Engineering, Xi'an Jiaotong University, 28 Xianning West Road, Xi'an, 710049, China.

*Corresponding author. Email: yangzx@mail.xjtu.edu.cn.

\begin{abstract}
Theoretical and experimental analyses are performed to investigate the pumping behaviour of a synchronal rotary multiphase pump (SRMP) at very high inlet gas volume fractions (GVFs). A comprehensive SRMP model is developed to predict the pump performance at very high inlet GVFs, including the steady-state behaviours and the transient distributions of interesting variables during pump operation. The experimental work is implemented using N32 oil and air as the working fluids to measure the global performance parameters of the SRMP at the inlet GVFs of 91\% 98\% and different differential pressures. The SRMP model is validated by comparison of the simulated and experimental results. The results show that the inlet GVF has a significant effect on the pump behaviour. At a given differential pressure, the leakage loss increases dramatically with the inlet GVF, which results in a significant decrease in the volumetric flow rate of the SRMP. Because of the large proportion of shaft power wasted by the high-pressure back flow, the SRMP exhibits lower pump efficiency at the higher inlet GVFs.
\end{abstract}

\section{Keywords}

Positive-displacement pump; gas volume fraction; two-phase flow; thermodynamic process; leakage; heat transfer. 


\section{Introduction}

Multiphase pumping is one of the most promising technologies in the petroleum industry, which essentially consists in adding hydraulic energy to unprocessed gas-liquid mixtures and transporting them through one pipeline. This technology makes longer tie-back distances possible for the production steam before separation in the processing facility, which is of special interest in deep water and onshore use, and in remote or hostile environments [1,2]. As using multiphase pumps to boost gas-liquid mixtures, multiphase pumping technology allows production to increase through the reduction of well-head pressure and the complete recovery of associated gases [3, 4]. It also allows significant cost savings through the simplification of conventional production facilities [5].

In recent years, because of the benefits of multiphase technology, the demand placed on the multiphase pump unit, which is the key device in the multiphase pumping system, has steadily increased. So far, several types of multiphase pump have been developed, which are categorised mainly as positivedisplacement pumps and rotodynamic pumps [6]. Compared to the rotodynamic multiphase pump, the positive-displacement multiphase pump exhibits more reliable performance in gas-liquid boosting, especially in applications with high pressure and high gas volume fraction (GVF). Based on its use in field applications around the world, the twin-screw multiphase pump is the most successful positivedisplacement pump in operation [7-9]. It has the proven ability to handle gas-liquid mixtures with any inlet GVF from 0 to nearly $100 \%[10,11]$. However, this pump is sensitive to the solid particles contained in the working fluids, and its manufacturing cost is also quite high because its rotors are formed by complex profiles [12].

The synchronal rotary multiphase pump (SRMP) is a new type of positive-displacement multiphase pump that is structurally simple and easy to manufacture. The SRMP design is based on the concept of 
the synchronal rotary mechanism that has been used in gas compressor [13-15]. The similar structure called revolving vane mechanism also has been used in the gas compressor and expander for refrigeration system[16, 17]. This type of mechanism has a unique structure in which the rotor is allowed to rotate together with the cylinder. In addition to its superior mechanical efficiency, the SRMP has the ability to handle gas-liquid mixtures with any inlet GVF due to its rotating suction and discharge ports [18]. Furthermore, due to the relative motions of the cylinder and rotor, solid particles contained in the working fluids are also easily squeezed out along the flow path of the working fluids.

Because the SRMP is a new type of multiphase pump, several studies have already been published. In the literature [19], the structural design and dynamic characteristics of the SRMP were theoretically investigated. The subsequent study focussed on the mechanical loss the SRMP and the preliminary experiment using liquid as working fluids[18]. In the literature[20], the pump behaviour of the SRMP with inlet GVFs of 0-90\% were theoretically and experimentally investigated. A theoretical model of the SRMP was developed in which the thermodynamic process was treated as an adiabatic process, and all of the chamber flows were assumed to be homogeneous gas-liquid flows. Such a SRMP model satisfactorily predicts the pump behaviour when the inlet GVF is no more than $90 \%$. However, when the inlet GVF rises above 90\%, the predication errors of the SRMP model increase significantly due to the change in the two-phase flow characteristics and the increase in the compression heat of the gas phase. Because the SRMP can handle two-phase fluids with a very high inlet GVF, it is quite important to develop a new SRMP model and implement further investigations of the pump behaviour under extreme operating conditions such as very high inlet GVFs up to almost $100 \%$.

In this study, further investigations are carried out that focus on SRMP behaviour when the inlet GVF is more than 90\%. A new SRMP model is developed to calculate all interesting flow variables and 
thermodynamic parameters during pump operation. The following experimental works are intended to verify the new model and analyse the thermodynamic process of the SRMP. Finally, the results of the simulations and experiments are discussed.

\section{Theoretical model of the SRMP}

Under the condition of very high inlet GVFs, the working process of the SRMP is more like that of the positive-displacement compressor. Similar to the theoretical models of positive-displacement compressors [21-24], the comprehensive model of the SRMP generally includes the geometrical characteristics, thermodynamic process, leakage flow, heat transfer and mechanical loss. Such a simulation model can be used to calculate the transient pressure and temperature in the working chambers and the steady flow rate and pump power consumption. In this section, the theoretical model of the SRMP for extreme conditions with very high inlet GVFs is developed. Compared to the model for conditions with lower inlet GVFs [20], the present model is developed in more detail to take into account the heat transfer between the working fluids and chamber walls, and it also includes a new leakage model using the separated two-phase flow model. Because the geometrical model and mechanical loss model of the SRMP are the same as those for conditions with lower inlet GVFs, the following formulae mainly concentrate on the thermodynamic process, leakage flow and heat transfer.

\subsection{Modelling of thermodynamic process}

As shown in Fig. 1, the SRMP basically consists of a rotor, a sliding vane and a cylinder with two end covers. The rotor and cylinder are eccentrically arranged such that the working chamber is formed by the walls of the rotor and the cylinder. The sliding vane divides the working chamber into a suction chamber and a discharge chamber. The suction chamber is connected to a suction port on the cylinder end cover, 
and the discharge chamber is connected to a discharge port on the rotor. During pump operation, the rotor is driven by the shaft that then carries the sliding vane to move, which in turn drives the cylinder to rotate. These motions cause variations in the chamber volumes that result in the suction and discharge processes. For a certain volume of working fluids, the complete working cycle including the suction and discharge processes lasts two shaft revolutions.
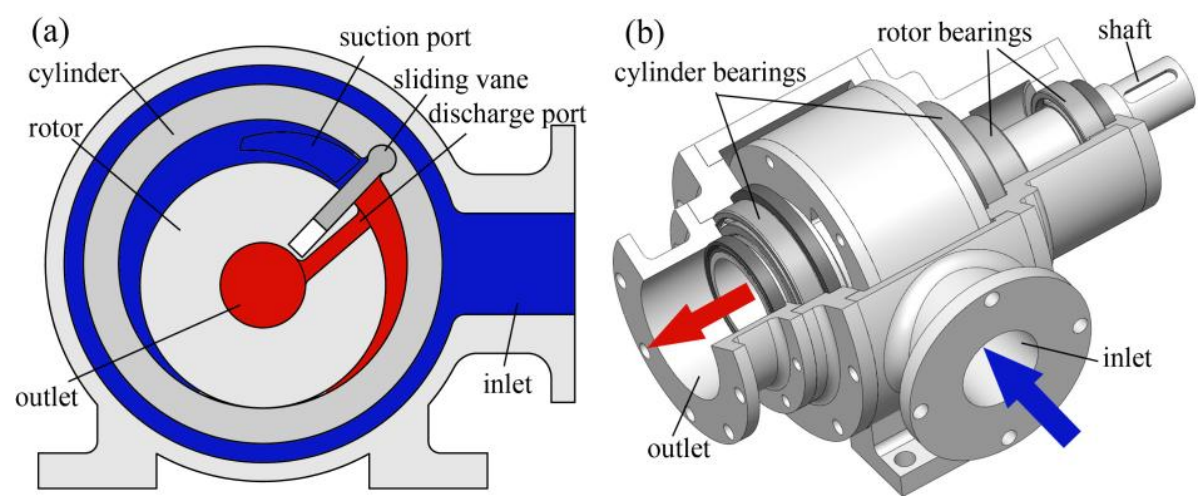

Fig. 1 Schematic of the SRMP: (a) sectional view, (b) cutaway view.

The thermodynamic process of the SRMP is based on an open system whose control volume is formed by the working chamber. During a working cycle, there exist mass and energy exchanges between the control volume and the outside space due to fluids flow and heat transfer. Neglecting the kinetic and potential energy of the working fluids, the energy conservation equation for the control volume can be derived from the first law of thermodynamics for an open system as follows:

$$
\frac{\mathrm{d} Q}{\mathrm{~d} \varphi}=\frac{\mathrm{d} U}{\mathrm{~d} \varphi}+\Sigma h_{\text {out }} \frac{\mathrm{d} m_{\text {out }}}{\mathrm{d} \varphi}-\Sigma h_{\text {in }} \frac{\mathrm{d} m_{\text {in }}}{\mathrm{d} \varphi}+p \frac{\mathrm{d} V}{\mathrm{~d} \varphi}
$$

in which $Q$ is the heat energy, $U$ is the internal energy, $h_{\text {out }}$ is the specific enthalpy of outflow, $h_{\text {in }}$ is the specific enthalpy of inflow, $m_{\text {out }}$ is the mass of outflow, $m_{\text {in }}$ is the mass of inflow, $V$ is the control volume, $p$ is the pressure, and $\varphi$ is the shaft angle. All of the thermodynamic and physical parameters refer to the gas-liquid fluids, which are assumed to be a homogeneous mixture. In the present study, it is assumed that the gas and liquid phase are in thermal equilibrium, and the gas phase is regarded as an ideal gas. 
Then, the differential equation of pressure and temperature of the working fluids in the control volume can be expressed as:

$$
\begin{gathered}
\frac{\mathrm{d} p}{\mathrm{~d} \varphi}=\frac{\frac{c_{\mathrm{p}} p}{x R_{\mathrm{g}}} \frac{\mathrm{d} V}{\mathrm{~d} \varphi}+\left[\frac{p(1-x)}{\rho_{\mathrm{L}}}-\frac{c_{\mathrm{p}} p V}{x m R_{\mathrm{g}}}\right] \frac{\mathrm{d} m}{\mathrm{~d} \varphi}+\sum\left[\frac{\mathrm{d} m_{\text {in }}}{\mathrm{d} \varphi} c_{\mathrm{p}}\left(T-T_{\mathrm{in}}\right)\right]-\frac{\mathrm{d} Q}{\mathrm{~d} \varphi}}{\left(1-\frac{c_{\mathrm{p}}}{x R_{\mathrm{g}}}\right)\left[V-\frac{(1-x) m}{\rho_{\mathrm{L}}}\right]} \\
\frac{\mathrm{d} T}{\mathrm{~d} \varphi}=\frac{p \frac{\mathrm{d} V}{\mathrm{~d} \varphi}+\sum\left[\frac{\mathrm{d} m_{\text {in }}}{\mathrm{d} \varphi} c_{\mathrm{p}}\left(T-T_{\text {in }}\right)\right]-\frac{\mathrm{d} Q}{\mathrm{~d} \varphi}}{m\left(x R_{\mathrm{g}}-c_{\mathrm{p}}\right)}
\end{gathered}
$$

In Eqs (2) and (3), $c_{\mathrm{p}}$ is the specific heat capacity of the two-phase mixture, $x$ is the gas mass fraction, $R_{\mathrm{g}}$ is the gas constant, $\rho_{\mathrm{L}}$ is the liquid density, $m$ is the mass of two-phase mixture, $T$ is the temperature, and $T_{\text {in }}$ is the temperature of inflow.

\subsection{Leakage flow model}

Referring to the analysis in the reference [20], there are two types of leakage gaps in the SRMP, which respectively are the radial clearance between the rotor and cylinder and the axial clearance between the cylinder and vane end. The geometrical details of the two types of leakage gaps can be found in the literature [20], and the models of the two types of leakage gaps are shown in Fig. 2. For each of the leakage gaps, as the magnitude of the gap height is relatively small compared to that of the gap width and length, the leakage flow therein can be modelled as one-dimensional two-phase flow through a narrow channel with a rectangle section. Under the condition of a higher inlet GVF, the compressibility of the two-phase mixture is taken into account as it has a large influence on the leakage flow.

(a)

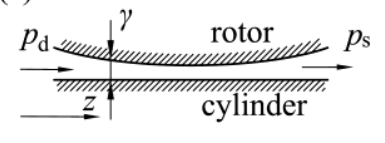

(b)

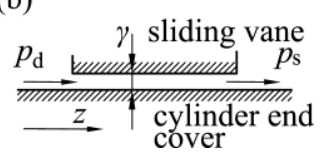

Fig. 2 Models of leakage gaps: (a) rotor radial gap, (b) vane end gap. 
The separated two-phase flow model is used to derive the leakage flow equations, in which the liquid and gas phases are considered individually. From the conservations of mass, momentum and energy, a set of leakage flow equations along the flow direction can be derived as follows:

$$
\left\{\begin{array}{l}
{\left[\frac{1}{\rho_{\mathrm{G}}}+\frac{1}{S}\left(\frac{\partial S}{\partial \rho_{\mathrm{G}}}\right)\right] \frac{\mathrm{d} \rho_{\mathrm{G}}}{\mathrm{d} z}+\frac{1}{\alpha u_{\mathrm{L}}} \frac{\mathrm{d} u_{\mathrm{L}}}{\mathrm{d} z}+\frac{1}{\alpha \gamma} \frac{\mathrm{d} \gamma}{\mathrm{d} z}=0} \\
\frac{\mathrm{d} p}{\mathrm{~d} z}+x G u_{\mathrm{L}}\left(\frac{\partial S}{\partial \rho_{\mathrm{G}}}\right) \frac{\mathrm{d} \rho_{\mathrm{G}}}{\mathrm{d} z}+[x S G+(1-x) G] \frac{\mathrm{d} u_{\mathrm{L}}}{\mathrm{d} z}-\left(\frac{\mathrm{d} p}{\mathrm{~d} z}\right)_{\mathrm{F}}=0 \\
c_{\mathrm{p}} \frac{\mathrm{d} T}{\mathrm{~d} z}+x S u_{\mathrm{L}}^{2}\left(\frac{\partial S}{\partial \rho_{\mathrm{G}}}\right) \frac{\mathrm{d} \rho_{\mathrm{G}}}{\mathrm{d} z}+\left(x S^{2}-x+1\right) u_{\mathrm{L}} \frac{\mathrm{d} u_{\mathrm{L}}}{\mathrm{d} z}=0
\end{array}\right.
$$

in which $S$ is the slip ratio, $\rho_{\mathrm{G}}$ is the gas density, $G$ is the mass velocity, $\alpha$ is the local gas void fraction, $u_{\mathrm{L}}$ is the velocity of liquid-phase, $\gamma$ is the gap height, and $z$ is the gap length. As proposed by Chung and Kawaji [25] for the two-phase flow through a small channel, the local gas void fraction can be calculated by an Armand-type correlation as follows:

$$
\alpha=C_{\mathrm{A}} \beta
$$

where $\beta$ is the GVF, and the coefficient $C_{\mathrm{A}}$ is expressed by the following equation, which is proposed by

Zhang et al. [26] for gas-liquid flow in a small rectangular channel

$$
C_{\mathrm{A}}=\frac{1}{1.2+0.38 e^{-1.39 / L a}}
$$

in which $L a$ is the non-dimensional Laplace constant. Then, the slip ratio can be expressed as:

$$
S=\frac{u_{\mathrm{G}}}{u_{\mathrm{L}}}=\frac{1}{C_{\mathrm{A}}}+\frac{x}{1-x} \frac{1-C_{\mathrm{A}}}{C_{\mathrm{A}}} \frac{\rho_{\mathrm{L}}}{\rho_{\mathrm{G}}}
$$

In Eq. (4), the two-phase friction pressure gradient can be expressed as the product of the two-phase friction multiplier and the friction pressure gradient if the liquid phase flows along in the leakage channel as follows:

$$
\left(\frac{\mathrm{d} p}{\mathrm{~d} z}\right)_{\mathrm{F}}=\left(\frac{\mathrm{d} p}{\mathrm{~d} z}\right)_{\mathrm{FL}} \phi_{\mathrm{L}}^{2}
$$

where $\phi_{\mathrm{L}}^{2}$ can be calculated by the Lockhart and Martinelli correlation [27] 


$$
\phi_{\mathrm{L}}^{2}=1+\frac{C}{X}+\frac{1}{X^{2}}
$$

for which the Lockhart-Martinelli parameter $X$ is defined as:

$$
X=\left[\left(\frac{\mathrm{d} p}{\mathrm{~d} z}\right)_{\mathrm{FL}} /\left(\frac{\mathrm{d} p}{\mathrm{~d} z}\right)_{\mathrm{FG}}\right]^{1 / 2}
$$

in which $\left(\frac{\mathrm{d} p}{\mathrm{~d} z}\right)_{\mathrm{FG}}$ represents the friction pressure gradient if the gas-phase flows alone in the leakage channel. Referring to the comparison between various types of $\mathrm{C}$-value correlations reported by Choi et al. [28], the C-value correlation proposed by Zhang et al. [26] is used for the present leakage gaps, which is expressed as

$$
C=21\left(1-e^{-0.674 / L a}\right)
$$

In Eqs. (8) and (10), the friction pressure gradients for the gas and liquid phases can be respectively calculated by the following equations:

$$
\begin{gathered}
\left(\frac{\mathrm{d} p}{\mathrm{~d} z}\right)_{\mathrm{FG}}=-\frac{f_{\mathrm{G}} x^{2} G^{2}}{\rho_{\mathrm{G}} \gamma} \\
\left(\frac{\mathrm{d} p}{\mathrm{~d} z}\right)_{\mathrm{FL}}=-\frac{f_{\mathrm{L}}(1-x)^{2} G^{2}}{\rho_{\mathrm{L}} \gamma}
\end{gathered}
$$

in which the single-phase friction factors $f_{\mathrm{L}}$ and $f_{\mathrm{G}}$ for the laminar flow and turbulent flow through the leakage gaps with rough surfaces are respectively expressed as:

$$
f_{i}=\left\{\begin{array}{lr}
24 / \operatorname{Re}_{i} & \operatorname{Re}_{i}<2300 \\
2\left[\left(8 / \operatorname{Re}_{i}\right)^{12}+1 /\left(a_{i}+b_{i}\right)^{3 / 2}\right]^{1 / 12} & \operatorname{Re}_{i} \geq 2300
\end{array}\right.
$$

where the subscripts $i=\mathrm{L}$ and $\mathrm{G}$, respectively, refer to the liquid phase and the gas phase, $R e$ is the Reynolds number, and the parameters $a$ and $b$ are given by

$$
\left\{\begin{array}{l}
a_{i}=\left\{2.457 \ln \left[\left(7 / \operatorname{Re}_{i}\right)^{0.9}+0.27 \varepsilon / 2 \gamma\right]\right\}^{16} \\
b_{i}=\left(37530 / \operatorname{Re}_{i}\right)^{16}
\end{array}\right.
$$

in which $\varepsilon$ is the surface roughness. 


\subsection{Heat transfer model}

In the SRMP, convective heat transfer exists between the working fluids and the surrounding chamber wall, which affects the thermodynamic process. During operation, the working fluids in the suction chamber are heated due to their temperature being lower than that of the chamber wall, whereas the working fluids in the discharge chamber are cooled due to their temperature being higher than that of the chamber. In the thermodynamic model formulated by Eq. (1), the heat energy per shaft angle can be expressed as:

$$
\frac{\mathrm{d} Q}{\mathrm{~d} \varphi}=\frac{A}{\omega} h\left(T_{\text {wall }}-T\right)
$$

where $A$ is the area of surrounding wall, $\omega$ is the angle velocity of rotor, $k$ is the convective heat transfer coefficient, and $T_{\text {wall }}$ is the temperature of the surrounding wall. When the SRMP operates under a steady condition, it is assumed that the value of $T_{\text {wall }}$ is constant throughout a work cycle and equal to the arithmetic mean of the suction and discharge temperatures. Due to the complex structure of the working chamber, it is difficult to evaluate the convective heat transfer coefficient exactly. In the present study, therefore, the empirical correlation of convective heat transfer proposed by Ma and Li [29] for rotary vane compressors is adopted, which is expressed as:

$$
k=0.023 \frac{\lambda}{D_{\mathrm{h}}} \operatorname{Re}^{0.8} \operatorname{Pr}^{0.4}\left(1+1.77 \frac{D_{\mathrm{h}}}{R_{\mathrm{h}}}\right)
$$

in which $\operatorname{Pr}$ is the Prandtl number, $D_{\mathrm{h}}$ is the equivalent hydraulic diameter, $R_{\mathrm{h}}$ is the average curvature radius, and the conductive heat transfer coefficient of gas-liquid mixture $\lambda$ can be calculated by the following formula:

$$
\lambda=\lambda_{\mathrm{L}} \frac{2 \lambda_{\mathrm{L}}+\lambda_{\mathrm{G}}-\frac{2 \beta}{100}\left(\lambda_{\mathrm{L}}-\lambda_{\mathrm{G}}\right)}{2 \lambda_{\mathrm{L}}+\lambda_{\mathrm{G}}+\frac{\beta}{100}\left(\lambda_{\mathrm{L}}-\lambda_{\mathrm{G}}\right)}
$$


where $\lambda_{\mathrm{G}}$ and $\lambda_{\mathrm{L}}$, respectively, are the conductive coefficients of the gas phase and liquid phase. The equivalent hydraulic diameter is expressed as:

$$
D_{\mathrm{h}}=\frac{4 V(\varphi)}{A(\varphi)}
$$

The average curvature radius is expressed as:

$$
R_{\mathrm{h}}=\frac{R_{\mathrm{cy}}+R_{\mathrm{ro}}}{2}
$$

where $R_{\text {cy }}$ is the cylinder radius and $R_{\mathrm{ro}}$ is the rotor radius. For the evaluations of the Reynolds number and Prandtl number, the characteristic velocity of the in chamber flow is calculated as follows:

$$
u_{\mathrm{h}}=\frac{\omega}{2}\left(R_{\mathrm{cy}}+R_{\mathrm{ro}}\right)
$$

\subsection{Numerical method}

The technical kernel of the simulation procedure is essentially to solve the thermodynamic model combined with the geometrical model, leakage model and heat transfer model of the SRMP by using the fourth-order Runge-Kutta method during a working cycle. After the simulation run, the transient pressure, temperature, density and local GVF in the working chamber at any shaft angle during a chamber lifetime can be obtained. Then, performance parameters such as the flow rate, power consumption and temperature increase can be calculated.

Fig. 3 shows the flow diagram of the simulation procedure. The procedure starts with the input of the geometrical and operating parameters of the SRMP and the physical properties of the fluids. Before the first iteration, the solution of the ideal thermodynamic model without leakage and heat transfer is made to initialise the distributions of pressure and temperature, which are the required inputs for solving the leakage and heat transfer models. After an iteration, if the transient pressure and temperature are not satisfied to the convergence criteria, the simulation moves to the next iteration, and the simulated results are used to initialise the distributions of pressure and temperature for the next iteration. When the 
transient pressure and temperature both converge, the iteration is accomplished and the simulation moves to the next step for calculations of flow rate and power consumption along with pump efficiency combined with the dynamic model of the SRMP. Finally, the procedure ends with the output of the simulated results.

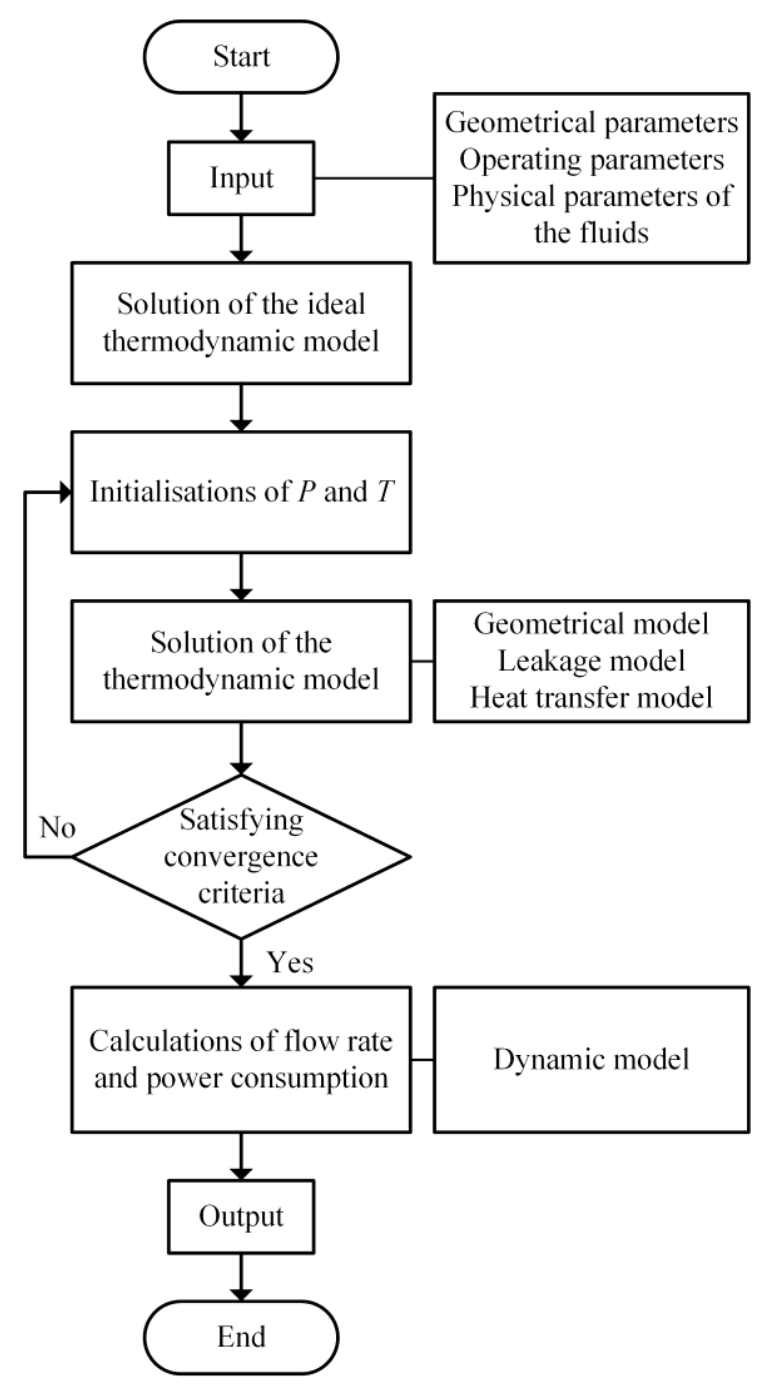

Fig. 3 Flow diagram of the simulation procedure.

\section{Experimental work}

Fig. 4 shows a schematic of the test bench of the present experimental work. The SRMP prototype is driven by a variable-speed motor. A torque-speed transducer is coupled between the motor and SRMP for measurements of the shaft speed and torque. According to the flow sequence, the gas phase is supplied 
by an air compressor while the liquid phase is injected by an oil pump from an oil tank. Flow rates of the gas and liquid phases can be adjusted respectively by ball gate valves set along the pipelines. The gasphase flow and the liquid-phase flow are mixed in a static mixer in front of the pump suction. The gasliquid mixture is pumped into a buffer tank after the pump discharge and then depressurised by a main choke valve. After this depressurisation, the liquid phase is injected into an oil tank with a cooling loop for recycling, and the gas phase is released back to the atmosphere.

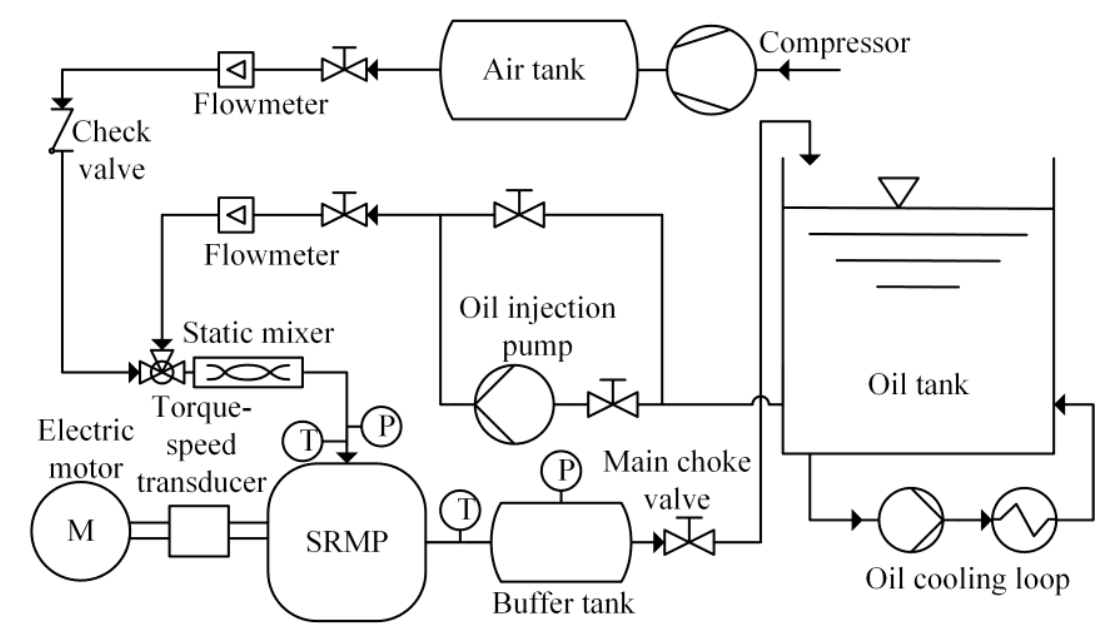

Fig. 4 Experimental bench.

The present experimental work is conducted to measure the steady-state performance of the SRMP under conditions of very high inlet GVFs by using N32 oil and air as the working fluids. The test range of inlet GVF is $0.9 \sim 0.98$, and the test range of differential pressure is $0 \sim 2 \mathrm{MPa}$. The operating specifications and geometrical parameters of the SRMP prototype are shown in Table 1. In the above test bench, several measurements can be made, such as the suction and discharge pressures, the inflow and outflow temperatures, the volumetric flow rates of both phases as well as the inlet GVF and the shaft power consumption. The uncertainties of these measurements are shown in Table 2. 
Table 1 Operating specifications and geometrical parameters of the SRMP prototype

\begin{tabular}{ll}
\hline Item & Value \\
\hline Rated shaft speed (rev/min) & 800 \\
Temperature at inlet $\left({ }^{\circ} \mathrm{C}\right)$ & 40 \\
Suction pressure $(\mathrm{MPa})$ & 0.2 \\
Discharge pressure $(\mathrm{MPa})$ & $0.2 \sim 2.2$ \\
Inlet gas volume fraction & $0.9-0.98$ \\
Volumetric displacement $\left(\mathrm{cm}{ }^{3} / \mathrm{rev}\right)$ & 158.3 \\
Rotor radius (mm) & \\
Cylinder radius $(\mathrm{mm})$ & 57 \\
\hline
\end{tabular}

Table 2 Uncertainties of measurements

\begin{tabular}{ll}
\hline Variable & Uncertainty \\
\hline Suction pressure & $< \pm 1 \mathrm{kPa}$ \\
Discharge pressure & $< \pm 4 \mathrm{kPa}$ \\
Liquid flow rate & $< \pm 0.05 \mathrm{~m}^{3} / \mathrm{h}$ \\
Gas flow rate & $< \pm 0.03 \mathrm{~m}^{3} / \mathrm{h}$ \\
Temperature & $< \pm 0.3^{\circ} \mathrm{C}$ \\
Inlet GVF & $< \pm 0.0094$ \\
\hline
\end{tabular}


Pump flow rate $\quad< \pm 0.08 \mathrm{~m}^{3} / \mathrm{h}$

Shaft power $\quad< \pm 10 \mathrm{~W}$

\section{Results and discussions}

To investigate the working performance of the SRMP, the volumetric flow rate, shaft power consumption and temperature increase of the working fluids were calculated by using the pump simulation model. These performance parameters of the SRMP were also measured in the experiment and finally compared to the simulated results to validate the theoretical model.

\subsection{Pump flow rate}

The volumetric flow rate of the SRMP can be calculated by subtracting the leakage flow rate from the theoretical flow rate. In this study, these volumetric flow rates are all defined under the inlet condition.

The theoretical flow rate of the SRMP is equal to the volumetric flow rate without leakage as follows:

$$
q_{\mathrm{th}}=\frac{n V}{60}
$$

where $n$ is the shaft rotating speed, and $V$ is the volumetric displacement per shaft revolution.

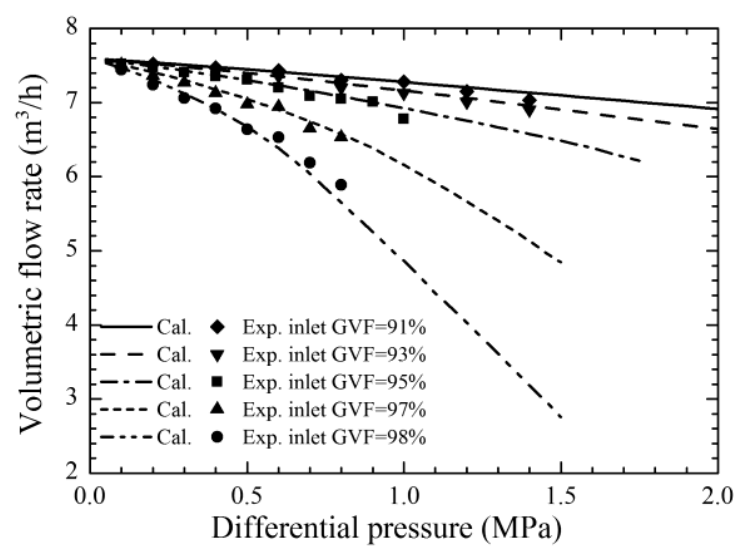

Fig. 5 Simulated and experimental net flow rates at different inlet GVFs and differential pressures.Fig. 5 shows the simulated and experimental net flow rates at different inlet GVFs and differential pressures. The symbols represent the measured data points, whereas the lines are generated 
by the numerical simulation of the SRMP. For each of the inlet GVFs, the simulation range of differential pressure is extended to a higher value to better show the trend of the net flow rate. From the comparison between the simulated and experimental results, it can be seen that the calculated flow rates agree well with the experimental results, although there are some discrepancies. It can also be observed that for a given inlet GVF, the net flow rate presents a declining trend as the differential pressure is increased. This occurs because during the pump operation, the higher differential pressure causes more inner leakage loss between the suction and discharge chambers. Furthermore, from comparisons between the five simulated curves in Fig. 5, it is found that the declining rate of the net flow rate increases dramatically when the inlet GVF is increased. This indicates that except the differential pressure, the inlet GVF also has a significant effect on the net flow rate and the leakage loss of the SRMP.

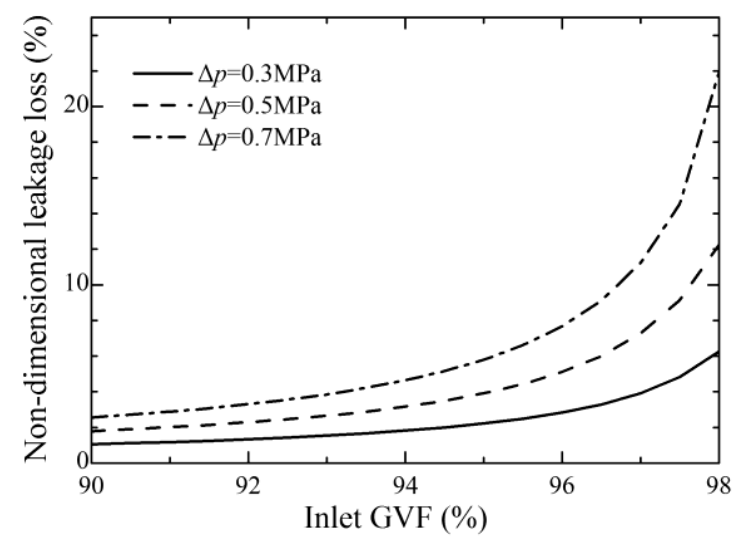

Fig. 6 Variation in non-dimensional leakage loss with the inlet GVF at different differential pressures.

Fig. 6 shows the variation in the non-dimensional leakage loss (the ratio of the average leakage flow rate to theoretical flow rate) with the inlet GVF at different differential pressures. When the inlet GVF is increased, the non-dimensional leakage loss increases similarly to an exponential function, especially at the higher differential pressure. Referring to the literature [30], because the flow sections of leakage gaps are extremely small, the pressure drop through the leakage channel is dominated by the friction pressure 
drop caused by the shear stress of the fluids. Thus, we can obtain a detailed explanation of the effect of inlet GVF on the leakage by analysing the friction pressure drop of the leakage flow.

According to the present simulation results of leakage flows, the Reynolds numbers of both the liquid and gas phases are found to be less than 2300 over the calculated range of differential pressure and inlet GVFs. Thus, the formula for the friction factor for laminar flow is used to calculate the single friction pressure drop. Referring to Eqs. (8) (14), the mass velocity of leakage flow is given as follows:

$$
G=-\frac{\gamma^{2}}{12(1-x) \phi_{\mathrm{L}}^{2} \nu_{\mathrm{L}}}\left(\frac{\mathrm{d} p}{\mathrm{~d} z}\right)_{\mathrm{F}}, x<1
$$

in which $v_{\mathrm{L}}$ is the kinematic viscosity of the liquid phase.

Fig. 7 shows the variation in the mass velocity of leakage flow through the rotor radial leakage gap at different inlet GVFs and a pressure difference of $0.5 \mathrm{MPa}$. At a given pressure difference between the discharge and suction chambers, the mass velocity of the two-phase leakage flow increases with the inlet GVF, which indicates that the volumetric leakage flow rate therein is also increased. Referring to Eq. (23), for a certain leakage gap and a given frictional pressure drop, the mass velocity of leakage flow is related to three parameters: the liquid mass fraction, the two-phase friction multiplier and the kinematic viscosity of liquid phase. It is easily found that these three parameters are all in inverse proportion to the mass velocity. Obviously, the increase in the inlet GVF causes a decrease in the liquid mass fraction, which contributes to the increase in the mass velocity as in Fig. 7. However, as shown in Fig. 8, the product of the liquid mass fraction and the two-phase friction multiplier is increased when the inlet GVF increases from $90 \%$ to $98 \%$. Thus, it can be deduced that the kinematic viscosity of the liquid phase decreases with the inlet GVF, and such decrease has a dominant effect on the mass velocity of leakage flow. 


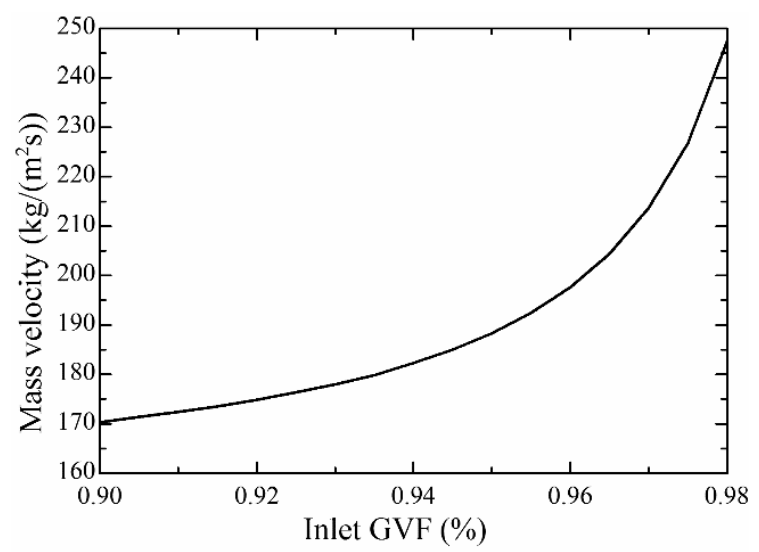

Fig. 7 Mass velocity of leakage flow through the rotor radial leakage gap at different inlet

GVFs and a pressure difference of $0.5 \mathrm{MPa}$

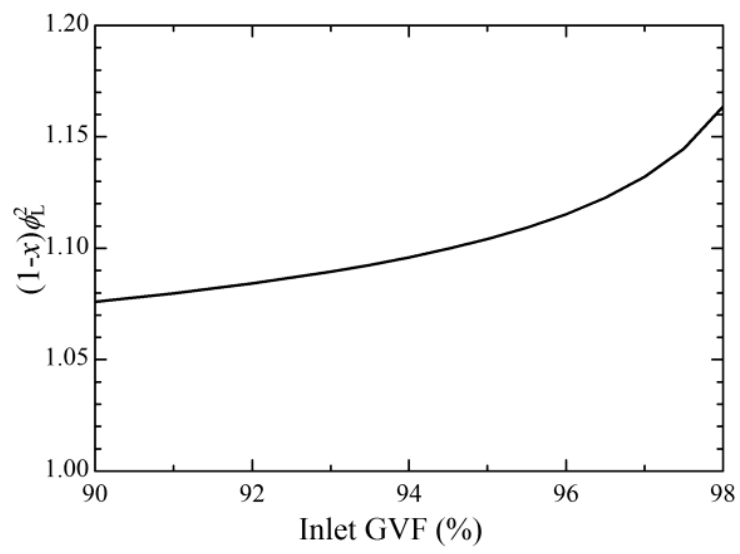

Fig. 8 Variation in the product of liquid mass friction and two-phase friction multiplier with

the inlet GVF at a pressure difference of $0.5 \mathrm{MPa}$.

\subsection{Temperature increase}

Fig. 9 shows the simulated and experimental temperature increases between the pump outlet and inlet at different inlet GVFs and differential pressures. The agreement between the simulated and experimental results is fairly good for each of the inlet GVFs. Fig. 9 also shows that at a given inlet GVF, the differential temperature increases with the differential pressure due to the increase in the compression heat of the gas phase. Furthermore, when the inlet GVF is increased, the curve of the temperature increase 
becomes steeper. This indicates that at a given differential pressure, the temperature of the working fluids in the discharge chamber increases with the inlet GVF.

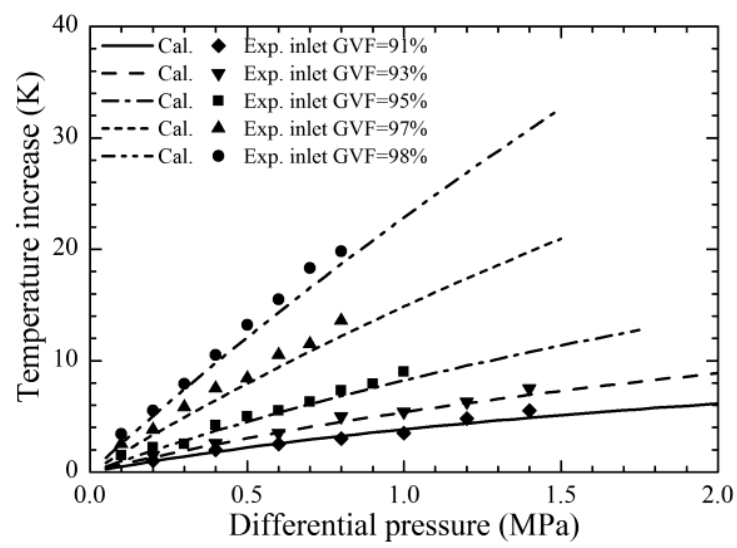

Fig. 9 Simulated and experimental temperature increases at different inlet GVFs and

\section{differential pressures.}

Under the present condition, the kinematic viscosity of the N32 oil used as the liquid phase of the working fluids decreases with the temperature, and the effect of pressure on the viscosity is negligible. This means that the increase in the inlet GVF causes a decrease in the kinematic viscosity of the liquid phase. Referring to Eq. (23), it can be concluded that at a given differential pressure, the increase in the inlet GVF causes an increase in the leakage loss through its effect on the temperature increase.

\subsection{Power consumption}

The shaft power consumption in the SRMP consists of the indicated power consumption and the mechanical loss due to friction between rubbing components. The mechanical loss can be calculated by the friction loss model as established in the literature [18]. The indicated power consumption of the shaft can be calculated by integrating the differential work over a working cycle as follows:

$$
P_{\mathrm{i}}=\frac{n}{60} \int_{0}^{4 \pi} p(\varphi) d V(\varphi)
$$



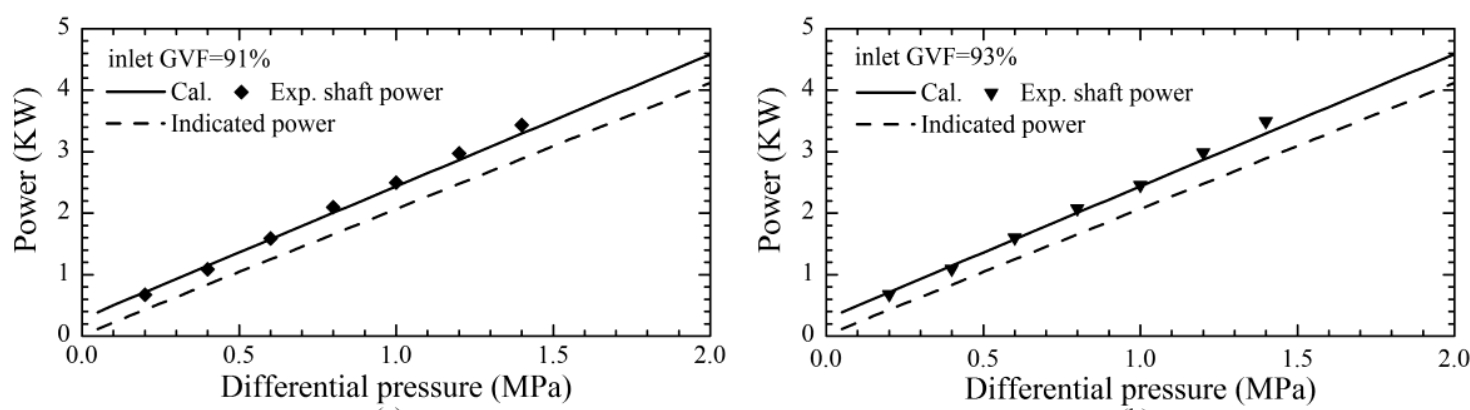

(a)
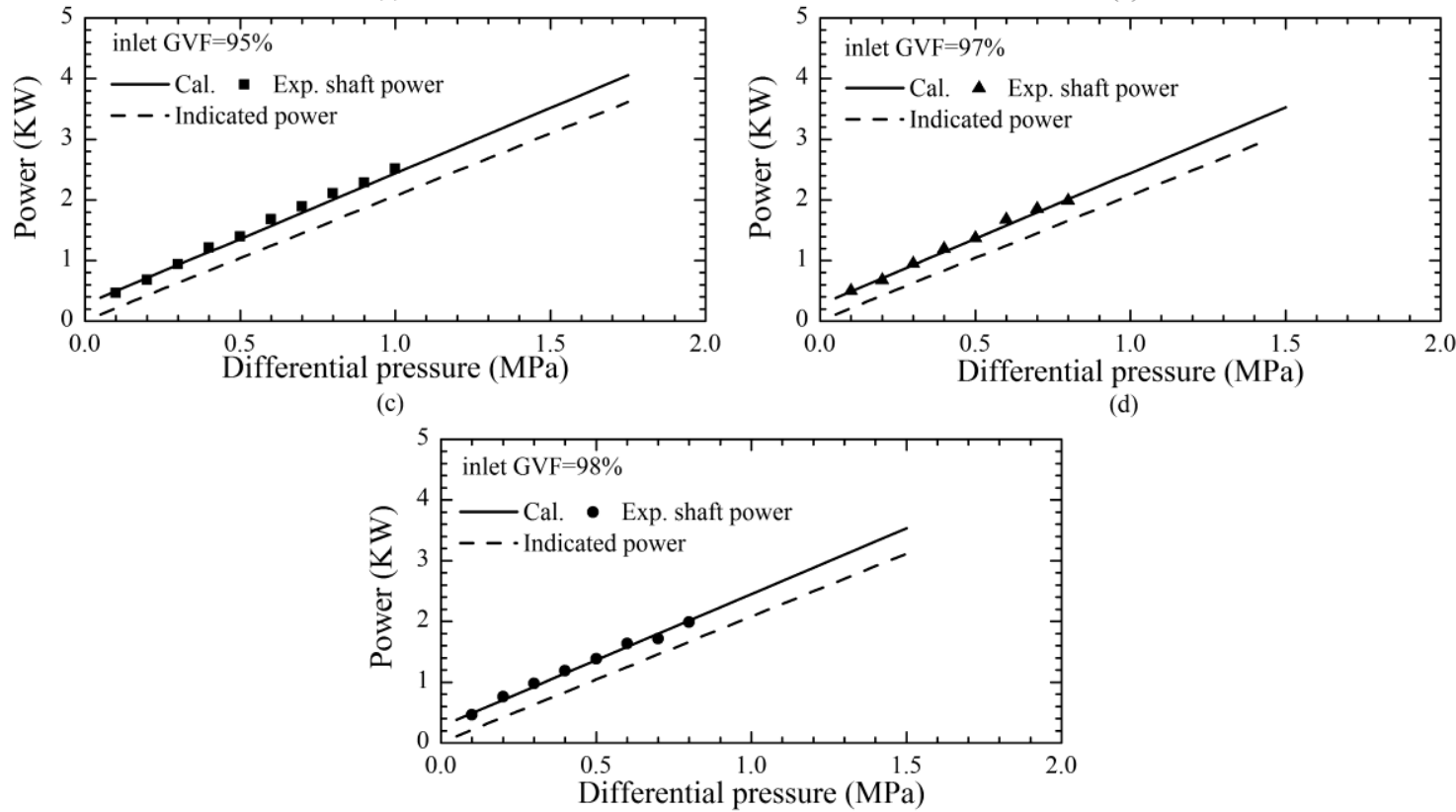

(d)

Fig. 10 Simulated and experimental shaft power consumptions at inlet GVFs of (a) 0.91, (b)

0.93, (c) 0.95, (d) 0.97and (e) 0.98 .

Fig. 10 shows the simulated and experimental shaft power consumptions at different inlet GVFs and differential pressures. In each of the panels in Fig. 10, the symbols represent the measured shaft power consumptions at different pressures, the solid line represents the simulated shaft power consumption, and the dash line represents the simulated indicated power consumption. Obviously, the difference between the shaft power and indicated power represents the mechanical loss. As can be seen, the simulated shaft powers agree well with those of the measured results over the entire range of data points, indicating that the theoretical model has achieved good accuracy in the theoretical prediction. At a given inlet GVF, the 
shaft power consumption increases almost linearly with the differential pressure due to the increased demand on the boosting power for the working fluids and the increased mechanical loss.

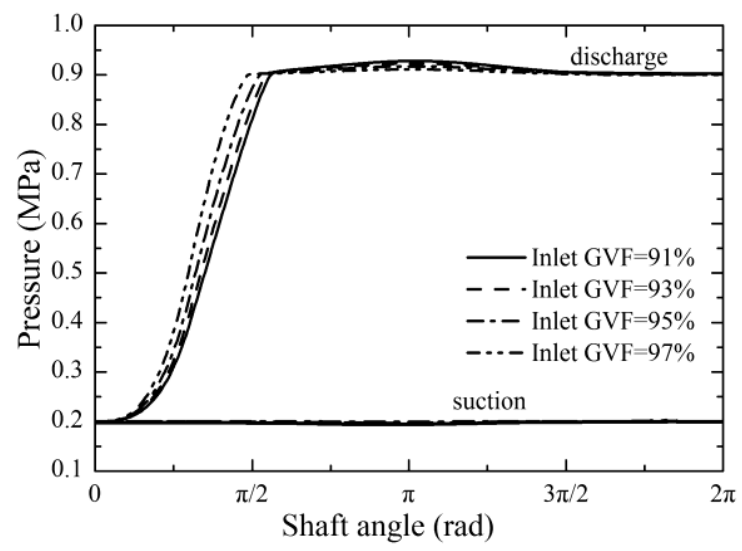

Fig. 11 Pressure curves in the suction and discharge chamber for different inlet GVFs.

Fig. 11 shows the pressure curves in the suction and discharge chambers over one shaft revolution at different inlet GVFs and a differential pressure of 0.7MPa. At a given GVF, the pressure in the suction chamber is almost constant throughout the suction process. According to the operation principle of the SRMP [18], there is no inner compression process during pump operation; thus, the increase in the pressure of the working fluids results from the back flow of high-pressure fluids from the outlet. Thus, the pressure in the discharge chamber initially increases dramatically and then reaches the value of discharge pressure at about a quarter of the shaft revolution. The pressure curves of the suction chamber for different inlet GVFs are rather close to each other. For the discharge chamber, the pressure increase in the back flow process is faster for the higher GVFs, and the pressures in the discharge process at the different inlet GVFs are almost equivalent. According to the definition of Eq. (24), the value of the indicated power is determined by the variations of the pressure in the working chambers and the chamber volume. In Fig. 11, at each inlet GVF, the area formed by the two pressure curves is in direct proportion to the indicated power consumption. Thus, it can be deduced that the indicated power consumption increases with the inlet GVF. However, according to the geometric characteristics of the SRMP, because 
the variation in the chamber volume within the shaft angle range of $0 \sim \pi / 2$ is small, the increase in the indicated power consumption is small for this shaft angle range. Therefore, it can be observed in Fig. 10 that the indicated power curves for the different inlet GVFs are almost equivalent. Besides, according to the literature [18], the friction loss of the SRMP is determined by the shaft rotation speed and differential pressure. In such a case, it can be concluded that there is almost no change in the shaft power consumption of the SRMP when the inlet GVF is increased.

\subsection{Pump efficiency}

The pump efficiency is defined as the ratio of the effective power consumption to the shaft power consumption. The effective power consumption is equal to the power exerted on the working fluids at the net flow rate and can be given as:

$$
P_{\mathrm{e}}=\frac{(1-x) q_{\mathrm{m}}}{\rho_{\mathrm{L}}}\left(p_{\mathrm{d}}-p_{\mathrm{s}}\right)+x q_{\mathrm{m}} \int_{p_{\mathrm{s}}}^{p_{\mathrm{d}}} \frac{1}{\rho_{\mathrm{G}}} \mathrm{d} p
$$

in which $q_{\mathrm{m}}$ is the mass flow rate, and $p_{\mathrm{d}}$ and $p_{\mathrm{s}}$ are, respectively, the suction and discharges pressures.

Then, the pump efficiency can be expressed as:

$$
\eta=\frac{P_{\mathrm{e}}}{P_{\mathrm{sh}}} \times 100 \%
$$

Fig. 12 shows the simulated effective power consumptions of the SRMP at different inlet GVFs and differential pressures. It can be observed that at a given inlet GVF and differential pressure, the effective power is much smaller than the indicated power consumption. The difference between the effective power and indicated power is equal to the additional power consumption, which is the power exerted on the high-pressure back flow. At a given inlet GVF, when the differential pressure is increased, the additional power consumption is increased due to the increased compression ratio of gas phase and leakage flow rate. Thus, it can be observed from Fig. 12 that for each inlet GVF, the effective power is smaller than the indicated power, and the slope rate of the curve of effective power is decreased with the 
differential pressure. Furthermore, it can also be seen that the curve of effective power consumption declines with the inlet GVF, which means that the effective power decreases with the inlet GVF. Fig. 13 shows the detail of different power consumptions at different inlet GVFs and a differential pressure of 1.0 MPa. The shaft power consumption consists of the friction power, additional power and effective power. Referring to the discussion in section 4.1, at a given differential pressure, the leakage flow rate increases with the inlet GVF, and as a result, the effective power consumption decreases with the inlet GVF. When the inlet GVF is increased, the increase in the additional power consumption results from both the increased compressibility of the two-phase working fluids and the increased leakage loss.

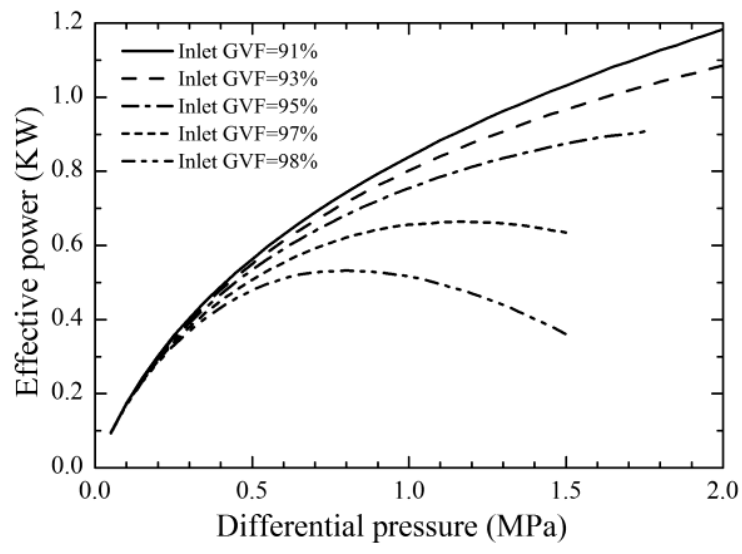

Fig. 12 Effective power consumption of the SRMP at different inlet GVFs and differential pressures.

Fig. 14 shows the simulated pump efficiency for different inlet GVFs and differential pressures. At a given inlet GVF, the curve of pump efficiency starts from a lower value, increases to a peak value and then decreases with the increase in differential pressure. Referring to the above analysis of power consumption, at a lower differential pressure, the indicated power is very small and the frictional loss occupies a large proportion of the shaft power consumption, which results in lower pump efficiency. When the differential pressure is increased, because of the increased proportion of indicated power, the pump efficiency is increased until the peak. Thereafter, the pump efficiency decreases with the increase 
in differential pressure due to the increased additional power consumption and leakage loss. Furthermore, as shown in Fig. 13, at a given differential pressure, because the shaft power consumption remains almost constant and the effective power is decreased when the inlet GVF is increased, the pump efficiency decreases with the inlet GVF. As shown in Fig. 14, at an inlet GVF of 98\%, the highest pump efficiency is only about $40 \%$. When the differential pressure is increased to $1.5 \mathrm{MPa}$, the pump efficiency decreases to less than $10 \%$. Thus, it can be concluded that the efficiency of the SRMP is lower when handling gasliquid fluids with a very high GVF.

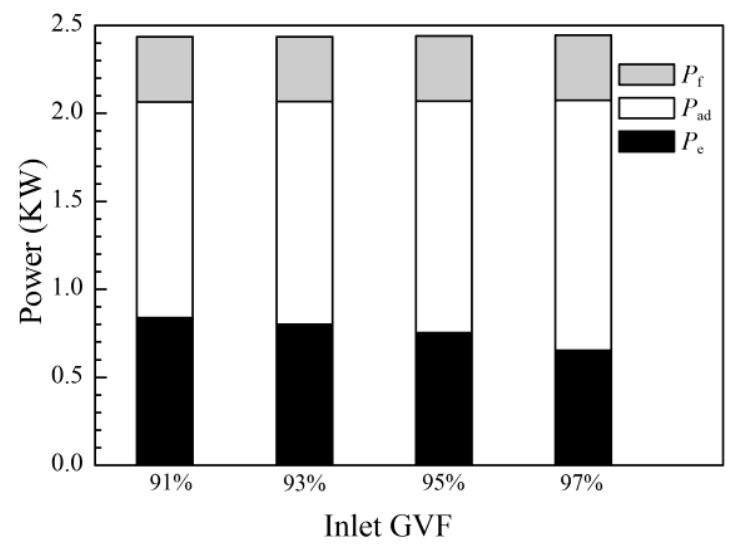

Fig. 13 Power consumption of the SRMP at different inlet GVFs and a differential pressure of

0.1 MPa.

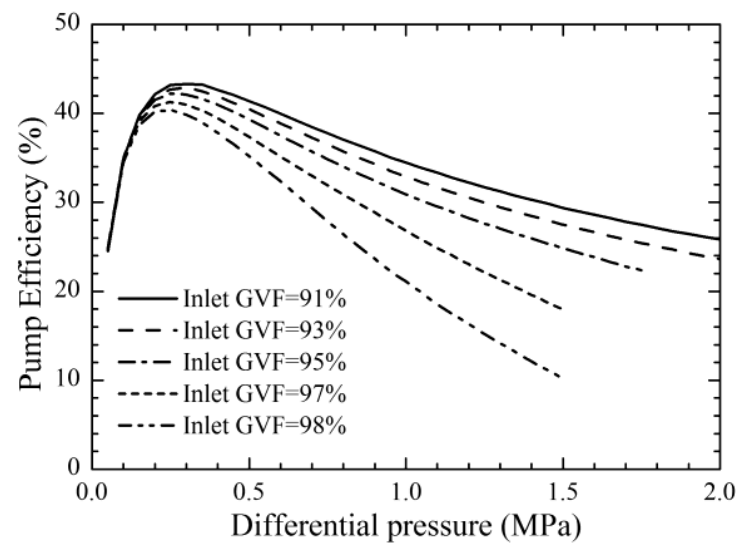

Fig. 14 Pump efficiency at different inlet GVFs and differential pressures. 


\section{Conclusion}

A new theoretical SRMP model is developed to predict pump performance at very high inlet GVFs, including the steady-state behaviour and the transient distributions of interesting variables during pump operation. The experimental work, accomplished on an SRMP prototype using a mixture of N32 oil and air as the working fluids, mainly focuses on measurements of volumetric flow rates, temperature increases and shaft power consumptions of the SRMP at inlet GVFs of 91\% 98\% and differential pressures of $0 \sim 1.5 \mathrm{MPa}$. Comparisons between the simulated and experimental results are made to validate the theoretical model. The agreement between the simulated and experimental results is fairly good, indicating that the theoretical model has achieved good accuracy in the theoretical prediction of pump performance.

During an increase of the inlet GVF from $91 \%$ to $98 \%$, the steady-state behaviour of the SRMP distinctly changes. At a given differential pressure, the volumetric flow rate of the SRMP decreases dramatically with the inlet GVF due to the increased leakage loss. When the inlet GVF is increased, the increase in the leakage loss results from the decreased mass fraction and liquid viscosity of the liquid phase. At a very high inlet GVF, the liquid phase is unable to absorb the compression heat of the gas phase, which results in a significant increase in the temperature of the two-phase mixture in the discharge chamber. The temperature increase directly results in the decrease of liquid viscosity, which causes an increase in leakage loss. At a given differential pressure, the shaft power consumption of the SRMP remains almost unchanged for the different inlet GVFs. However, the effective power consumption decreases significantly with the inlet GVF due to the increase in the additional power needed to discharge the high-pressure back flow during the discharge process. Because a large proportion of the shaft power 
is wasted by the high-pressure back flow, the SRMP exhibits lower pump efficiency at the higher inlet

GVFs.

The present experimental investigation provides evidence of the operational capability of the SRMP at very high inlet GVFs, which is meaningful for the field application of this new type of multiphase pump. However, the present experimental work is limited in its measurement of global parameters. As a further step, an experimental investigation of the pressure and temperature distributions and the fluid composition inside the chambers and gaps is recommended to reveal additional details of pump behaviour and the flow characteristics. These findings will be reported in a future paper.

\section{Acknowledgments}

The authors acknowledge financial support from the National Natural Science Foundation of China

(NSFC) (Grant No. 51406150) and the National Science Foundation for Post-doctoral Scientists of China

(Grant No. 2013M542348).

\section{Nomenclature}

$\begin{array}{ll}A & \text { area of surrounding wall }\left[\mathrm{m}^{2}\right] \\ C & \text { coefficient of Lockhart-Martinelli's correlation [-] } \\ C_{\mathrm{A}} & \text { coefficient of Armand-type correlation [-] } \\ c_{\mathrm{p}} & \text { specific heat capacity of gas-liquid mixture }[\mathrm{J} /(\mathrm{kg} \mathrm{k})] \\ D_{\mathrm{h}} & \text { hydraulic diameter }[\mathrm{m}] \\ f & \text { friction factor }[-] \\ G & \\ & \\ & \end{array}$




\begin{tabular}{|c|c|}
\hline$k$ & convective heat transfer coefficient $\left[\mathrm{J} /\left(\mathrm{m}^{2} \mathrm{~K}\right)\right]$ \\
\hline$L a$ & non-dimensional Laplace constant [-] \\
\hline$m$ & mass $[\mathrm{kg}]$ \\
\hline$n$ & shaft speed [rev/min] \\
\hline$P_{\mathrm{e}}$ & effective power consumption [W] \\
\hline$P_{\mathrm{i}}$ & indicated power consumption [W] \\
\hline$P_{\text {sh }}$ & shaft power consumption [W] \\
\hline $\operatorname{Pr}$ & Prandtl number [-] \\
\hline$p$ & pressure $[\mathrm{Pa}]$ \\
\hline$Q$ & heat energy $[\mathrm{J}]$ \\
\hline$q_{\mathrm{th}}$ & theoretical volumetric flow rate $\left[\mathrm{m}^{3} / \mathrm{h}\right]$ \\
\hline$q_{\mathrm{m}}$ & mass flow rate $[\mathrm{kg} / \mathrm{s}]$ \\
\hline$R_{\mathrm{cy}}$ & cylinder radius $[\mathrm{m}]$ \\
\hline $\operatorname{Re}$ & Reynolds number [-] \\
\hline$R_{\mathrm{h}}$ & curvature radius $[\mathrm{m}]$ \\
\hline$R_{\mathrm{g}}$ & gas constant $[\mathrm{J} /(\mathrm{kg} \mathrm{K})]$ \\
\hline$R_{\text {ro }}$ & rotor radius $[\mathrm{m}]$ \\
\hline$S$ & slip ratio [-] \\
\hline$T$ & temperature $[\mathrm{K}]$ \\
\hline$U$ & internal energy $[\mathrm{J}]$ \\
\hline$u$ & velocity $[\mathrm{m} / \mathrm{s}]$ \\
\hline$u$ & characteristic velocity $[\mathrm{m} / \mathrm{s}]$ \\
\hline
\end{tabular}




$\begin{array}{ll}V & \text { control volume }\left[\mathrm{m}^{3}\right] \\ X & \text { Lockhart-Martinelli parameter [-] } \\ x & \text { gas mass fraction [-] } \\ z & \text { length of leakage gap [m] }\end{array}$

Greek symbols

$\alpha \quad$ gas void fraction [-]

$\beta \quad$ gas volume fraction [-]

$\gamma \quad$ height of leakage gap [m]

$\varepsilon \quad$ surface roughness [m]

$\eta \quad$ Pump efficiency [\%]

$\lambda \quad$ conductive heat transfer coefficient $[\mathrm{J} /(\mathrm{m} \mathrm{K})]$

$v \quad$ kinematic viscosity $\left[\mathrm{m}^{2} / \mathrm{s}\right]$

$\rho \quad$ density $\left[\mathrm{kg} / \mathrm{m}^{3}\right]$

$\varphi \quad$ shaft angle [rad]

$\varphi^{2} \quad$ two-phase friction multiplier [-]

$\omega \quad$ angle velocity of rotor $[\mathrm{rad} / \mathrm{s}]$

Subscripts

G gas-phase

in inflow

L liquid-phase

out outflow 


\section{References}

[1] G. Hua, G. Falcone, C. Teodoriu, G.L. Morrison, Comparison of multiphase pumping technologies for subsea and downhole applications, Oil and Gas Facilities, 1 (2012) 36-46.

\section{http://dx.doi.org/10.2118/146784-PA}

[2] J. Falcimaigne, S. Decarre., Multiphase production : pipeline transport, pumping and metering, Editions Technip, Paris, 2008.

[3] A.H. Dogru, A.A. Hamoud, S.G. Barlow, Multiphase pump recovers more oil in a mature carbonate reservoir, Journal of Petroleum Technology, 56 (2004) 64-67. http://dx.doi.org/10.2118/83910-JPT

[4] R. Lastra, I. Johnson, Feasibility study on application of multiphase pumping towards zero gas flaring in Nigeria, in: Nigeria Annual International Conference and Exhibition, Society of Petroleum Engineers, Abuja, Nigeria, 2005. http://dx.doi.org/10.2118/98800-MS

[5] D.F. Dal Porto, L.A. Larson, Multiphase pump field trials demonstrate practical applications for the technology, SPE Production and Facilities, 12 (1997) 159-164. http://dx.doi.org/10.2118/36590-PA

[6] S.L. Cao, G.Y. Peng, Z.Y. Yu, Hydrodynamic design of rotodynamic pump impeller for multiphase pumping by combined approach of inverse design and CFD analysis, Journal of Fluids EngineeringTransactions of the Asme, 127 (2005) 330-338. http://dx.doi.org/10.1115/1.1881697

[7] E. Chynoweth, Twin screw pump is developed for multiphase applications, Process Eng. (London), 67 (1986) 27-31.

[8] D. Müller-Link, G. Rohlfing, Grown-up twin-screw multiphase pumps - from marginal to full size applications, in: 14th International Conference on Multiphase Production Technology, BHR Group Limited, Cannes, France, 2009. https://www.onepetro.org/conference-paper/BHR-2009-C1 
[9] D. Müller-Link, G. Rohlfing, H. Spelter, Twin screw pumps help improving oil recovery in mature fields and transfer heavy crude oil over long distances, Oil Gas Eur. Mag., 35 (2009) 127-131.

[10] F. Cao, T. Gao, S. Li, Z. Xing, P. Shu, Experimental analysis of pressure distribution in a twin screw compressor for multiphase duties, Experimental Thermal and Fluid Science, 35 (2011) 219-225.

\section{http://dx.doi.org/10.1016/j.expthermflusci.2010.09.004}

[11] K. Räbiger, T.M.A. Maksoud, J. Ward, G. Hausmann, Theoretical and experimental analysis of a multiphase screw pump, handling gas-liquid mixtures with very high gas volume fractions, Experimental Thermal and Fluid Science, 32 (2008) 1694-1701.

\section{http://dx.doi.org/10.1016/j.expthermflusci.2008.06.009}

[12] C.K. Dorenbos, D. Müeller-Link, A. Jäeschke, Sand Handling During Multiphase Operations With Twin-Screw Pumps, in: SPE International Thermal Operations and Heavy Oil Symposium, Society of Petroleum Engineers, Porlamar, Margarita Island, Venezuela, 2001. https://www.onepetro.org/conference-paper/SPE-69846-MS

[13] Z. Qu, X. Lin, J. Feng, H. Zhou, Theory of synchronal rotary compressor, in: International Compressor Engineering Conference Vol. C008, Purdue University, USA, 2004, pp. 1-5. $\underline{\text { http://docs.lib.purdue.edu/icec/1683/ }}$

[14] H. Yang, Z.C. Qu, H. Zhou, B.F. Yu, Study on leakage via the radial clearance in a novel synchronal rotary refrigeration compressor, International Journal of Refrigeration-Revue Internationale Du Froid, 34 (2011) 84-93.

http://dx.doi.org/10.1016/j.ijrefrig.2010.08.007

[15] H. Zhou, Z.C. Qu, H. Yang, B.F. Yu, Dynamic Model and Numerical Simulation for Synchronal Rotary Compressor, Journal of Fluids Engineering-Transactions of the Asme, 131 (2009) 041102. 


\section{http://dx.doi.org/doi:10.1115/1.3089534}

[16] A. Subiantoro, K.S. Yap, K.T. Ooi, Experimental investigations of the revolving vane (RV-I) expander, Applied Thermal Engineering, 50 (2013) 393-400.

http://dx.doi.org/10.1016/j.applthermaleng.2012.06.009

[17] K.M. Tan, K.T. Ooi, Experimental study of fixed-vane revolving vane compressor, Applied Thermal Engineering, 62 (2014) 207-214. http://dx.doi.org/10.1016/j.applthermaleng.2013.09.038

[18] X. Yang, Z. Qu, Y. Wu, Frictional loss studies and experimental performance of a new synchronal rotary multiphase pump, Journal of Fluids Engineering-Transactions of the Asme, 133 (2011) 041303. http://dx.doi.org/10.1115/1.4003986

[19] X. Yang, Z. Qu, Y. Wu, Working principle and dynamic characteristics of a synchronal rotary multiphase pump, J. Xi'an Jiaotong Univ., 44 (2010) 60-65.

[20] X. Yang, Z. Qu, X. Hu, Y. Wu, Theoretical and experimental performance analysis of a synchronal rotary multiphase pump with the inlet gas volume fractions of 0-0.9, Proceedings of the Institution of Mechanical Engineers Part a-Journal of Power and Energy, 226 (2012) 727-737.

\section{http://dx.doi.org/10.1177/0957650912452363}

[21] K.T. Ooi, T.N. Wong, A computer simulation of a rotary compressor for household refrigerators, Applied Thermal Engineering, 17 (1998) 65-78. http://dx.doi.org/10.1016/1359-4311(96)00013-0

[22] Y. Chen, N.P. Halm, E.A. Groll, J.E. Braun, Mathematical modeling of scroll compressors-part I: compression process modeling, International Journal of Refrigeration, 25 (2002) 731-750. http://dx.doi.org/10.1016/S0140-7007(01)00071-8

[23] N. Stosic, I.K. Smith, A. Kovacevic, Optimisation of screw compressors, Applied Thermal Engineering, 23 (2003) 1177-1195. http://dx.doi.org/10.1016/S1359-4311(03)00059-0 
[24] G. Bianchi, R. Cipollone, Theoretical modeling and experimental investigations for the improvement of the mechanical efficiency in sliding vane rotary compressors, Applied Energy, 142 (2015) 95-107.

http://dx.doi.org/10.1016/j.apenergy.2014.12.055

[25] P.M.Y. Chung, M. Kawaji, The effect of channel diameter on adiabatic two-phase flow characteristics in microchannels, International Journal of Multiphase Flow, 30 (2004) 735-761.

http://dx.doi.org/10.1016/j.ijmultiphaseflow.2004.05.002

[26] W. Zhang, T. Hibiki, K. Mishima, Correlations of two-phase frictional pressure drop and void fraction in mini-channel, International Journal of Heat and Mass Transfer, 53 (2010) 453-465. http://dx.doi.org/10.1016/j.ijheatmasstransfer.2009.09.011

[27] R.W. Lockhart, R.C. Martinelli, Proposed correlation of data for isothermal two phase, twocomponent flow in pipes, Chemical Engineering Progress, 45 (1949) 39-48.

[28] C.W. Choi, D.I. Yu, M.H. Kim, Adiabatic two-phase flow in rectangular microchannels with different aspect ratios: Part II - bubble behaviors and pressure drop in single bubble, International Journal of Heat and Mass Transfer, 53 (2010) 5242-5249.

\section{http://dx.doi.org/10.1016/j.ijheatmasstransfer.2010.07.035}

[29] G. Ma, H. Li, Rotary Compressors, China Machine Press, Beijing, 2003.

[30] C. Choi, M. Kim, Flow pattern based correlations of two-phase pressure drop in rectangular microchannels, International Journal of Heat and Fluid Flow, 32 (2011) 1199-1207.

http://dx.doi.org/10.1016/j.ijheatfluidflow.2011.08.002 


\section{Table captions}

Table 1 Operating specifications and geometrical parameters of the SRMP prototype.

Table 2 Uncertainties of measurements.

\section{Figure captions}

Fig. 1 Schematic of the SRMP: (a) sectional view, (b) cutaway view.

Fig. 2 Models of leakage gaps: (a) rotor radial gap, (b) vane end gap.

Fig. 3 Flow diagram of the simulation procedure.

Fig. 4 Experimental bench.

Fig. 5 Simulated and experimental net flow rates at different inlet GVFs and differential pressures.

Fig. 6 Variation in non-dimensional leakage loss with the inlet GVF at different differential pressures.

Fig. 7 Mass velocity of leakage flow through the rotor radial leakage gap at different inlet GVFs and a pressure difference of $0.5 \mathrm{MPa}$.

Fig. 8 Variation in the product of liquid mass friction and two-phase friction multiplier with the inlet

GVF at a pressure difference of $0.5 \mathrm{MPa}$.

Fig. 9 Simulated and experimental temperature increases at different inlet GVFs and differential pressures.

Fig. 10 Simulated and experimental shaft power consumptions at inlet GVFs of (a) 0.91, (b) 0.93, (c) 0.95 , (d) 0.97 and (e) 0.98 .

Fig. 11 Pressure curves in the suction and discharge chamber for different inlet GVFs.

Fig. 12 Effective power consumption of the SRMP at different inlet GVFs and differential pressures.

Fig. 13 Power consumption of the SRMP at different inlet GVFs and a differential pressure of 0.1 MPa.

Fig. 14 Pump efficiency at different inlet GVFs and differential pressures. 